\title{
EU Health Policy, Coherence, Stakeholder Diversity and Their Impact on the EMA
}

\author{
Denis Horgan $^{a} \quad$ Alastair Kent $^{b}$ \\ ${ }^{a}$ European Alliance for Personalised Medicine, Brussels, Belgium; ${ }^{b}$ Genetic Alliance, \\ London, UK
}

\section{Keywords}

Health policy · Innovation · Regulation · European Medicines Agency · European

Ombudsman $\cdot$ Stakeholders

\begin{abstract}
Innovation is a major pillar in bringing new, targeted medicines to patients. In the health arena, this means the translation of knowledge into what we can call "value." The latter covers the value to patients but must also take into account value to healthcare systems, society and, of course, manufacturers. The EU has recognised that innovations in healthcare can contribute to the health and well-being of citizens and patients through access to new products, services and treatments with added value. It is also aware that in order to stimulate development, there is a need to facilitate the translation of scientific advances into innovative medicinal products that meet regulatory standards, accelerate patients' access to new therapies and are affordable to Member States' health systems. Early dialogue between technology developers, regulators, health technology assessment and, where relevant, pricing bodies will promote innovation and quicker access to medicines at affordable prices, for the benefit of patients. But while uncertainties in healthcare policy still exist, a request by the European Ombudsman to the European Medicines Agency to provide more information about its early dialogue procedures questions the above "early dialogue" principal. It raises the issue of what the EU aims to do with its health regulation in bringing innovation to the patient. Is this added uncertainty about the hereto trusted role of the EMA a welcome development? Not necessarily.
\end{abstract}




\section{Background}

A formal request during the summer of 2017 to the European Medicines Agency (EMA) to provide more information about its early dialogue procedures was courteously worded, but carried the same threat as a match casually tossed into bone-dry woodland.

The request, citing risks that such "pre-submission activities" create "some perception of bias," came from the EU Ombudsman, Emily O’Reilly [1].

The Ombudsman's letter listed in careful detail questions about the EMA practice of "engaging with individual medicine developers before the Agency receives applications for marketing authorisations from them." The letter remained scrupulously impartial in asking the questions - seeking, as it were, reassurance that the processes serve public rather than private interests. But the mere fact that the Ombudsman felt it necessary to raise the issue demonstrated clearly just how far Europe remains from a mature understanding of what it is trying to do with its own health regulation.

"Insofar as these activities help the development and availability of high-quality, effective and acceptably safe medicines, they benefit patients and serve the public interest," the letter conceded. But, it went on, "such activities may pose some risks, such as that the eventual decisions by EMA on the authorisation of medicines may be influenced by what has been discussed during the meetings with medicine developers prior to receiving their marketing authorisation application."

The implication is clear: the Ombudsman is insinuating that the regulators at EMA cannot be trusted - despite the fact that the agency is itself a fully fledged EU body, created by EU legislation, and established precisely to achieve the very obvious balance that she herself alludes to and presumably also aspires to. A body, moreover, that has earned a reputation worldwide for the quality of its procedures, its sense of judgement, and its conclusions [2].

The Ombudsman's investigation into EMA procedures will doubtless continue into 2018, but it is already igniting some hot debate in Europe about the relationship between science, innovation, regulation, stakeholders, and political legitimacy [3].

\section{The Rise of Public Health Collaboration}

The uncertainty displayed by the Ombudsman about the reliability of EMA is emblematic of a much wider undercurrent of doubt about Europe's approach to health and health regulation. At times, and among some very vocal stakeholders, this uncertainty results in a sort of legislative schizophrenia, characterised by strident demands for more harmonisation and controls, accompanied by equally vigorous rejection of any of the centralisation that such developments would require [4].

Uncertainty over health policy is clearly not desirable, but in Europe it is, unfortunately, not altogether surprising. Historically, health has had an uncomfortable time of it in the EU. The concept of health was very deliberately retained by member states as a national competence from the outset. It was scarcely mentioned in the founding treaties, and then only as a justification for national refusals to allow free movement of workers or goods [5].

Gradually, and in a minimalist manner, scanty allusions to public health considerations found their way into successive treaty revisions, and from 1997, a Council of the Ministers of Health began to meet on an occasional basis. These meetings resulted in acts such as "decisions of the Member States meeting within the Council" or non-binding resolutions of debatable force and giving rise to highly uneven implementation [6]. Following the signature of the Single European Act, instruments of this kind, and with equally questionable legal impact, began to proliferate. 
Public health was not given a place until the Treaty on European Union, offering at least a way to formal cooperation between member states in this area, while health protection was elevated to the rank of a formal objective [7]. But it was only with the most recent version, the Treaty of Lisbon that came into effect in 2009, that the EU stipulated that "a high level of human health protection shall be ensured in the definition and implementation of all Community policies and activities" - complemented by the (hesitantly and incompletely adopted) Charter on Fundamental Rights (which stated that "Everyone has the right of access to preventive health care and the right to benefit from medical treatment" - but still qualified that right as "under the conditions established by national laws and practices") [8].

\section{Limitations to the EU's Health Agenda}

So there are now mentions of health in official EU documents - but they all continue to emphasise the strict limitations. As the EU's own legislative summary makes clear, "The EU does not define health policies, nor the organisation and provision of health services and medical care" [9]. The EU's role is only "to complement national policies" [10].

In addition, the various strands of health-related policy are split widely across the EU's institutions: the ministerial health council is no more than a subsidiary of the employment and social affairs council (and does not even enjoy direct input into the reflections of EU finance and economy ministers); within the Commission, departments (and their commissioners) covering research, enterprise, digital technology, trade, or social or regional affairs each have their own health fief, alongside the health department, which has no hierarchical position of oversight; and in the European Parliament, health is similarly split between committees on consumer protection, research, industry, social affairs and so on.

The consequent "halfway houses" for accountability and responsibility remain the uncomfortable background to EU discussions of health, and they continue to hamper the formation of coherent policy. The controversy that arose in the summer over the safety of eggs in the face of reports of contamination with fipronil is a neat demonstration of the ambiguity of EU engagement with health [11].

Despite the titular responsibility held by a European Commissioner for protecting the population, and the existence of a supposedly foolproof hazard-reporting system at EU level, the egg saga highlighted how much responsibility remains at national level, how much falls between cracks, and how much misunderstanding this unsatisfactory situation results in.

The Dutch discovery of fipronil contamination degenerated into confused and often contradictory accounts from other national authorities of the provenance of the suspect goods, and about when countries became aware, and how they acted. The widely differing views of individual member states on the level of risk were equally eloquent of the inchoate state of policy. When, in the middle of the holiday season, the Commissioner convened an emergency meeting of health ministers for the rentrée, the responses included dismissive remarks from French and Danish regulators that the risk level was too low to be of concern. The underlying tensions drove Vytenis Andriukaitis, the health commissioner, to say publicly: "Blaming and shaming will bring us nowhere and I want to stop this. We need to work together to draw the necessary lessons and move forward instead of losing energy on finger pointing" [12]. 


\section{Uncertainties in Healthcare Policy Still Exist}

Good decision-making in such a context would be challenging even in relatively simple matters. But the highly complex area of personalised medicine finds itself buffeted by a regulatory tempest as it attempts to emerge from its chrysalis [13] - and the Ombudsman's intervention in the issue of early dialogue is not making things any smoother.

That intervention is all the more ironic in that - amid all the uncertainties of the EU's attempts to tackle health in general terms - one specific area is closely, and by and large effectively, regulated: the authorisation of medicines. In this health-related area, the EU legislated firmly - but it did so on a much more solid basis than the flimsy grounds of EU competence on health [14]. The EU invoked the importance of allowing effective free circulation of goods in its medicines legislation, thus overcoming the ambiguities and constraints hampering health policy. And as a result, it has developed laws and standards for medicines that are widely and rightly regarded as effective and beneficial. Interlinked systems provide for scrupulous and expert examination of the supporting evidence for any medicine, and imaginative efforts are underway to ensure that the systems remain capable of dealing with the innovations that are made possible by the evolution of science [15].

But the clear parentage of this regulatory framework for medicines, born out of the more stable legislative context of the single market, has not conferred immunity to the hazards of EU healthcare uncertainties. The legislation on medicines is - by association - frequently subject to the same strains that affect healthcare policy in general. And the ambiguities that flow from the troubled genesis of EU healthcare engagement over the last six decades continue to be a handicap today.

That is a disadvantage, and it is important that disadvantage does not turn into a threat to innovation.

\section{Is Juncker Concerned?}

The sad reality is that EU health policy has never really found its feet. Jean-Claude Juncker ignored the repeated well-meaning (if often vacuous or ineffectual) expressions from ministers, MEPs and officials - as well as from his own predecessors as President of the European Commission, and omitted health entirely from his list of priorities when he took office. He went on to display massive indifference to the nuances of health policy in the way he allocated responsibilities among his commissioners [16].

The impact of this omission was so great that many healthcare stakeholders have begun to fear that the EU is going to drop health policy altogether - or at least to abandon any attempt at coherence. Patient groups, heavily dependent on EU funding, had their fears intensified by a 2017 policy document on the future of Europe in which one possible scenario envisaged an EU oblivious to health matters [17]. European Patients' Forum in particular was concerned that its mission of contributing to high-quality healthcare and "embracing innovation" would be prejudiced. They sought reassurances at the highest level, with a letter to Juncker calling for "strong high-level leadership inside the Commission, with specific responsibility for health" in "a dedicated directorate."

"Mainstreaming health in other Commission directorates will not work without stimulus, guidance, knowledge, expertise and leadership from a strong directorate for health," they said. It requires health expertise "within the Commission," and "working in concert with the health community." "National governments cannot address the threats to health and health services alone," they argued. But they received little more than platitudes and lip service in response [18]. 
Privately, too, the scientific community and the research-based drug industry have been increasingly critical of the lack of EU coherence in health policy, and of limited delivery of support on the ground for innovation. The criticisms are emerging more and more into the public domain too. UCB's CEO insisted at a public meeting in June that the industry needed incentives and a more outcomes-driven environment. EFPIA now routinely calls for "a much more integrated health research environment" and systems "that support innovation while balancing realistically benefit and risk" [19].

\section{Innovation Set to Suffer}

Advancing the challenging mission of evidence-based innovative medical science in this context is more difficult than it ought to be - more difficult than it could be, if a clearer European understanding was reached of what is really at stake.

Some of the pervading uncertainty has sprung from a deep-seated suspicion of private enterprise involvement in health and healthcare - a strand in European politics that is linked to the strong socialist inspiration behind much of modern Europe's admirable social structures and traditions. At its best, this determination to defend broad social values in the interests of the majority has been beneficial over decades. But unthinking application of hostility to enterprise can be counterproductive, not only to innovation, but even to the society itself.

In the area of EU health, stakeholders have often been very active, sometimes with valuable results - as in the increased recognition that has been won for patients' representation, for example in EMA committees [20].

The pressure derives in most cases from good intentions. But it can have perverse unintended consequences.

The exclusion of healthcare from the EU services directive showed clearly how some hyper-sensitivities can occlude judgment. Healthcare was taken out of the legislation at draft stage, because of concerns that its inclusion was tantamount to seeing healthcare as a product. But its exclusion flew in the face of the EU's fundamental objective of maximising collaboration across borders [21].

Analogous hyper-sensitivities have obtruded into decision-making in other healthrelated areas. Most conspicuously, EU policy-making on biotechnology has been a model of muddled thinking driven by emotion rather than evidence, and the EU's international credibility has been called into question because of the paralysis that has ensued over EU attitudes to GM technology and its products [22].

The impartiality and even integrity of the food safety authority, EFSA, has repeatedly been impugned by activists with an avowedly anti-science agenda. Strong emotions have also been at the heart of attempts to influence the EU debate on animal testing, with animal rights groups seeking to limit animal use irrespective of the clear scientific consensus that medicines development still requires some animal tests until satisfactory alternatives are developed [23].

Even the data privacy debates in the EU saw pressures to abandon rational treatment of research data because the obsessive concern over the only tenuously related social media intrusion blinded reflection on any other consideration [24]. Next-generation sequencing is coming under similar hostile scrutiny from pressure groups who claim to be representing the public interest - and presume to have a better understanding of what individual patients want or need than do the individual patients themselves [25].

In short, there is a range of issues where stakeholders, doubtless often meaning well, act as self-appointed guardians of the public interest, and risk cutting off their noses to spite their faces - or, indeed, cutting off patients' noses to spite patients' faces. 


\section{The Realities of Delivery}

This is not to overlook much of the great work done by many NGOs. But there needs to be a more profound reflection on just what some groups are trying to achieve. Is it to win an argument for the betterment of society, or is it merely to win applause for spectacular action, as in a circus?

The reflection needs to take account of the realities and feasibilities of what can actually be delivered. At times, there are asks which might make sense on paper and sound good as slogans, but cannot be so easily realised. The proliferating claims for rights are a good example. It is easy to make a declaration about rights for cancer patients, right to access of treatment, rights to patient empowerment, or even the right to have a return on investment. Proclaiming a right is very different from implementing the mechanisms needed to make a reality out of the aspirations.

Crudely put, the "rights" of cancer patients are strictly and objectively limited by factors that no amount of protestation can influence: the state of scientific understanding of particular cancers, or the characteristics of individual patients and the stage of their disease; even the hot-button topics of access to and affordability of care are limited by time, place, resources, etc. And the right to a return on investment depends on innumerable factors beyond the direct control of investors - everything from product quality, research efficiency or market conditions to earthquake or fire.

The ease with which "rights" can be proclaimed these days carries the risk of breeding a certain disdain for reality, and a facile presumption that earnestness of appeal somehow equates to availability of a solution. The presumption is often associated with a suspicion - or even conviction - that established institutions are somehow allied against the interests of the people. This phenomenon has been increasingly evident in the recent rise of populist political movements, often parading simplistic solutions that win support among undiscerning audiences [26].

\section{Is the Ombudsman's Involvement Really Necessary?}

So what does the Ombudsman initiative bring to the party, and why does it matter?

It matters because this is delicate territory...

Whose views is the Ombudsman representing in questioning the impartiality of the EMA early dialogue procedures? EMA is already fully conscious of the risks that she claims to be bringing new scrutiny to, and it takes measures to contain them. The same is true of the national regulatory agencies who tackle these risks in their own countries, and as constant contributors to the work of EMA. Similarly, health professionals deal every day with keeping the right balance between familiarity with therapeutic options and retaining their professional independence. And paying agencies and health technology assessment bodies are engaged in a continual search to refine their approaches to the process of evaluation.

The Ombudsman speaks of deciding "to conduct a strategic inquiry, on my own initiative, into the arrangements," and cites EMA's own description of the arrangements as if that constituted some prima facie evidence to support suspicions, noting that EMA "sees pre-submission meetings as a way to enable medicine developers to establish contact with the Agency staff who will be involved with the application."

The letter then goes on to argue that "Even if EMA were to ensure that its subsequent assessments of applications for marketing authorisations are objective and complete, there is still a risk that pre-submission activities create, in the eyes of the public, at least some perception of bias." 
This is a contentious approach. Even if the EMA procedures are watertight, the risk of some perception of bias among unidentified and unquantified members of the public is sufficient to justify a strategic inquiry, the Ombudsman maintains. By that logic, it takes only a handful of dissenting voices on the probity of any institution to justify a strategic inquiry into its affairs and conduct [27].

The "eyes of the public" to which the Ombudsman refers are not, in fact, too hard to identify. The European consumers bureau, BEUC, has said in the past that "great care is needed also over pre-submission meetings: these should not occur with individual companies." BEUC is of the opinion that "greater stakeholder involvement and participation bears the risk of giving disproportionate influence to the most affluent interested parties at the expense of other lesser resourced groups, introducing an inherent bias in favour of the industry at the expense of civil society organisations" [28].

The European public health alliance, EPHA, has offered similar thoughts: "It is imperative to guarantee the integrity and independence of HTA bodies while strengthening them so that they can effectively deliver ..." This needs, insists EPHA, strict conditions: "The necessary safeguards should be in place to guarantee there is no regulatory capture and that conflicts of interest are prevented, particularly, in the areas of early dialogue and scientific advice."

Prescrire also commented recently that "based on our experience in drug reviews, dialogues between the regulators and pharmaceutical companies are not necessary when the data are sufficiently robust and when clinical trials are designed to address important health needs."

It went on, in familiar terms, to warn that "a serious risk of institutional capture exists if there is no strong policy in place to avoid conflicts of interest (product team leaders directly in contact with companies without any interface, many oral explanations behind closed doors). In addition, as the content of early dialogue discussions remains strictly confidential it is impossible to draw any conclusion. Without transparency on lessons learnt and access to facts, data and rationale such opaque initiatives should not be used to build new policies and guidelines" [29].

There is nothing intrinsically wrong with these organisations expressing their views. They are all keen students of healthcare issues in general and medicines in particular, and are fully entitled to argue a case, even if the starting point is a demonstrably suspicious, and often negative, prejudice about the healthcare industry. What is more questionable is the response of the EU Ombudsman, in initiating a strategic inquiry apparently on the basis of a selection of uniformly hesitant opinions about the merits of early dialogue.

\section{The Value of Early Dialogue and Collaboration}

A degree of trust is necessary in the expert bodies of the EU that are demonstrably working effectively. EMA's principal objective is to serve the best interests of EU citizens. Promoting early dialogue is fully in line with that objective. It aims to ensure that resources are not wasted - either by public or private researchers or by EMA itself - in new product development [30].

Moreover, the EMA provisions for early dialogue are not just innocuous - they are positively beneficial, and spring from a form of common sense that appears on occasions to be sadly lacking in public commentary. As EMA itself points out, scientific advice and protocol assistance are particularly useful to medicine developers working in uncharted waters on innovation, such as when EU guidelines or guidance documents offer insufficient relevant detail, or when the developer chooses to deviate from the available guidance in its development plan - as is often the case with innovative therapies [31]. 
So valuable is early dialogue seen to be that as of July 2017 EMA instituted a new form of partnering with the European Network for Health Technology Assessment - another body composed entirely of impartial scientists and regulators. This, explains EMA, aims to allow medicine developers to obtain feedback from regulators and HTA bodies on their evidencegeneration plans to support decision-making on marketing authorisation and reimbursement of new medicines at the same time. The objective is to help generate optimal and robust evidence that satisfies the needs of both regulators and HTA bodies.

This is a step ahead of the previous parallel scientific advice procedure operated by EMA and HTA bodies, which was more ponderous in that it required medicine developers to contact member states' HTA bodies individually.

"Interactions between medicines' developers, regulators and HTA bodies or other possible stakeholders to discuss the development plan means that evidence can be generated to meet the needs of respective decision-makers as efficiently as possible. This facilitates patient access to important new medicines and hence benefits overall public health," says EMA, pointing to the benefits that more structured interaction brings in terms of increased mutual understanding and problem-solving ability between EMA and HTA bodies [32].

The need for better collaboration is widely established as a prerequisite to giving innovation a better chance, in Europe, and around the developed world. In the US, where concerns over high drug prices - and flagrant episodes of abusive exploitation by some companies have fuelled scepticism over industry motivation, the prominent American cancer organisation ASCO has been pioneering constructive reflection on solutions, and its conclusions point to closer collaboration among all parties.

ASCO says it "stands ready to assist in efforts to arrive at solutions that ensure access, affordability, and innovation." It insists that any solutions must preserve patients' access to care and foster innovation. "There should," it says, "be a real and consistent relationship between the benefits of a particular drug to patients and its cost. A single, reliable framework for comparing treatment options is essential and will require more comparative effectiveness research to determine how well new drugs perform relative to existing alternatives, along with their impact on diverse populations; a broader range of clinical trial endpoints that accurately reflect patients' quality of life; and big data projects... to compare drug safety and effectiveness in real-world settings."

It has proposed that "a diverse group of stakeholders from across the health-care sector (1) identify, prioritise, and test potential solutions to address the affordability of cancer drugs and (2) help define a standard approach to assessing the value of drugs that could be applied broadly to inform drug pricing and reimbursement" [33].

And a strong social orientation does not automatically mean hostility to innovation. Even stakeholders with powerful social commitments recognise the need to improve the situation. Two of the leading mutual insurance organisations in Europe, for instance, ESIP and AIM, have spoken out on the need for closer contacts among all parties to ease access to innovative medicines, highlighting "the importance of voluntary cooperation between member states on health technology assessment, exchanges of information with and between pricing and reimbursement bodies and stakeholders, and joint negotiations and procurement." In their comments to the EU consultation on the future of HTA in Europe, they welcomed "the focus on assessing the relevance of the EU framework in encouraging real innovation in accordance with patients' needs." AIM Executive Director Menno Aarnout has questioned the need for rushing into exploring adaptive pathways, but he has made clear that "exploring the existing options for early access of a drug to the market, defining what are unmet medical needs and clarifying the qualifying criteria for early market access for the benefit of the patients should be the first steps" [34]. 
The Ombudsman's adumbration of notional risks concludes: "These risks must be managed." But as EMA and many other parties to this affair will doubtless point out, "these risks" are managed already.

\section{EU Can Continue Strong Support for Healthcare}

Not all EU initiatives relating to medicines are counterproductive. In the area of rare diseases, civil society, institutional stakeholders and member states have found ways of working constructively together to share expertise, to promote the development of treatments and to ease access to them. The EU's orphan drug rules are rightly regarded as a huge success in incentivising innovation. The recent launch of cross-border reference networks of expertise on rare and complex diseases is already underpinning that work and taking it ahead in new directions of specialised diagnosis and care [35].

The European Court of Justice has, through judicial activism, also played a strong role in advancing European healthcare, both in requiring the EU to legislate on cross-border patient rights, and - in so doing - triggering new levels of cross-border collaboration on e-health and health technology assessment [36].

Contrary to the impression that the Ombudsman's initiative may give, the EU has had and can continue to have - a strongly supportive role in healthcare. It has stepped up where member states could not have done it alone. The resulting coordination to develop science, to translate innovation, to systemise marketing authorisation requirements for medicines and to facilitate quality testing and trials has shown a positive aspect of the EU, and should serve as inspiration and encouragement for more joined-up approaches to tackle new challenges.

The best hope, therefore, is that the initiative by the Ombudsman will in the end bring more light than heat to the discussion of EU health regulation - and illuminate a path towards a more secure understanding of how the balance can be struck between regulation and innovation.

\section{Disclosure Statement}

The author has no conflicts of interest to declare.

\section{Funding Sources}

No funding sources.

\section{References}

1 Letter from the European Ombudsman to the European Medicines Agency opening strategic inquiry OI/7/2017/KR into pre-submission activities organised by the Agency. July 17, 2017. https://www.ombudsman.europa.eu/cases/correspondence.faces/en/81555/html.bookmark.

2 Vicini P, Fields O, Lai E, et al: Precision medicine in the age of big data: the present and future role of large-scale unbiased sequencing in drug discovery and development. Clin Pharmacol Ther 2016;99:198-207.

3 EU watchdog concerned drug agency EMA may be too close to companies. July 19, 2017. http://www. euronews.com/2017/07/19/eu-watchdog-concerned-drug-agency-ema-may-be-too-close-to-companies. 
-4 Franklin PK: Public health within the EU policy space: a qualitative study of Organized Civil Society (OCS) and the Health in All Policies (HiAP) approach. Public Health 2016;136:29-34.

5 Negrouk A, Lacombe D, Meunier F: Diverging EU health regulations: the urgent need for co-ordination and convergence. J Cancer Policy 2017, in press.

6 Guy M, Sauter W: The History and Scope of EU Health Law and Policy. Norwich, University of East Anglia, Centre for Competition Policy, 2016.

7 Vollaard H, van de Bovenkamp H, Sindbjerg Martinsen D: The making of a European healthcare union: a federalist perspective. J Eur Public Policy 2016;23:157-176.

8 Emmerling T, Rys A: The development of EU health policy: treaty basis, health acquis and history; Emmerling T, Kickbusch I, Told M (eds): The European Union as a Global Health Actor. New Jersey, World Scientific, 2016, pp 21-91.

9 EUR-Lex: Public health. http://eur-lex.europa.eu/summary/chapter/public_health.html?root_default=SUM_ 1_CODED\%3D29).

10 European Union: Health. 2017. https://europa.eu/european-union/topics/health_en.

11 Banks M: EU Commission monitoring fipronil egg crisis. The Parliament: Politics, Policy and People Magazine, August 11, 2017. https://www.theparliamentmagazine.eu/articles/news/eu-commission-monitoringfipronil-egg-crisis.

12 EU Commissioner calls for eggs summit after contamination scare. Business Times, August 11, 2017. http:// www.businesstimes.com.sg/consumer/eu-commissioner-calls-for-eggs-summit-after-contamination-scare.

13 McKinsey report: Personalized Medicines: The Path Forward. 2013. http://www.mckinsey.com/ /media/ mckinsey/dotcom/client_service/pharma\%20and $\% 20$ medical $\% 20$ products /pmp $\% 20$ new/pdfs / mckinsey\%20on\%20personalized\%20medicine\%20march\%202013.ashx.

14 Pignatti F, Ehmann F, Hemmings R, et al: Cancer drug development and the evolving regulatory framework for companion diagnostics in the European Union. Clin Cancer Res 2014;20:1458-1468.

15 Hauray B: From regulatory knowledge to regulatory decisions: the European evaluation of medicines. Minerva 2017;55:187-208.

16 Brooks E: The "last chance for social Europe": the European Pillar of Social Rights can only work if integrated into the EU's existing policies. LSE, European Politics and Policy (EUROPP) Blog, May 22, 2017.

17 European Commission: White Paper on the Future of Europe. News, July 17, 2017. https://ec.europa.eu/ commission/news/white-paper-future-europe-2017-jul-17_en.

18 European Patients Forum: Dear President Juncker, EU Health Collaboration is crucial for Europe's future. June 6, 2017. http://www.eu-patient.eu/News/News/dear-president-juncker-eu-health-collaboration-is-crucialfor-europes-future/.

19 European Federation of Pharmaceutical Industries and Associations: Partners in Research: implementing technology integration. February 15, 2016. https://www.efpia.eu/media/26027/efpia_partners-in-research_ implementing-technology-integration.pdf.

20 Bere N: PA03.04 Patient involvement in the evaluation of cancer medicines: the EMA experience. J Thorac Oncol 2017;12:S218-S219.

21 Barnard C: Unravelling the services directive. Common Market L Rev 2008;45:323-394

22 Davison J: GM plants: science, politics and EC regulations. Plant Sci 2010;178:94-98.

-23 Rollin F, Kennedy J, Wills J: Consumers and new food technologies. Trends Food Sci Technol 2011;22:99-111.

24 Rumbold JMM, Pierscionek B: The effect of the General Data Protection Regulation on medical research. J Med Internet Res 2017;19:e47.

25 PantS, Weiner R, Marton MJ: Navigating the rapids: the development of regulated next-generation sequencingbased clinical trial assays and companion diagnostics. Front Oncol 2014;4:78.

-26 Barugahare J, Lie RK: Understanding the futility of countries' obligations for health rights: realising justice for the global poor. BMC Int Health Hum Rights 2016;16:15.

-27 Sepodes B: Regulation of orphan medicinal products in Europe: history trends and challenges. Clin Ther 2016; 38:e7-e8.

28 BEUC: Open EFSA: BEUC response to the public consultation. 2014. http://www.beuc.eu/publications/beucx-2014-077_ipa_open_efsa-beuc_response_to_the_public_consultation.pdf.

29 Questionnaire for Administrations, Associations and Other Organisations. https://epha.org/wp-content/ uploads/2017/01/EPHAs-response-to-HTA-consultation_submitted-18-Jan..pdf.

30 European Medicines Agency: The European Medicines Agency: a well-established Agency of the EU protecting human and animal health for all EU citizens. July 14, 2016. http://www.ema.europa.eu/docs/en_GB/ document_library/Other/2016/10/WC500214053.pdf.

31 European Medicines Agency: Scientific advice and protocol assistance. http://www.ema.europa.eu/ema/ index.jsp?curl=pages/regulation/general/general_content_000049.jsp.

32 European Medicines Agency: Guidance for parallel consultation. June 30, 2017. http://www.ema.europa.eu/ docs/en_GB/document_library/Regulatory_and_procedural_guideline/2017/07/WC500230375.pdf.

33 ASCO: American Society of Clinical Oncology Position Statement on Addressing the Affordability of Cancer Drugs. Approved by the ASCO Board of Directors June 1, 2017. https://www.asco.org/sites/new-www.asco. org/files/content-files/blog-release/documents/2017-ASCO-Position-Statement-Affordability-CancerDrugs.pdf. 
34 AIM: We welcome Council conclusions on balancing the pharmaceutical system in the EU. February 13, 2016. https://www.aim-mutual.org/mediaroom/we-welcome-council-conclusions-on-balancing-the-pharmaceutical-system-in-the-eu/.

-35 Annemans L, Aymé S, Le Cam Y, et al: Recommendations from the European Working Group for Value Assessment and Funding Processes in Rare Diseases (ORPH-VAL). Orphanet J Rare Dis 2017;12:50.

36 Vollaard H, Sindbjerg Martinsen D: The rise of a European healthcare union. Comp Eur Politics 2017;15:337352. 